\title{
El derecho a la no autoincriminación en el procedimiento administrativo sancionador: un estudio
} a la luz de la jurisprudencia del TJUE

\section{The right not to incriminate oneself in administrative sanctions procedure: a study in the light of the case- law of the European Court of Justice}

AlBerto Picón ARRANZ

Universidad de Valladolid

albicon11@gmail.com

@) (®) Este artículo está sujeto a una licencia “Creative Commons ReconocimientoNo Comercial" (CC-BY-NC).

DOI: https://doi.org/10.24197/ree.79.2022.367-388

Resumen: El derecho a la no autoincriminación se configura como un derecho fundamental integrado en el más amplio derecho de defensa y está reconocido en los tratados internacionales más importantes de nuestro entorno jurídico. Su operatividad en el marco del proceso penal no ofrece dudas, y tampoco su traslado al ámbito del procedimiento administrativo sancionador. Sin embargo, el objeto de este trabajo será realizar un análisis sobre el alcance del derecho a guardar silencio y a no confesarse culpable dentro del procedimiento administrativo, no solo sancionador, sino también de inspección, así como su operatividad en relación con las personas jurídicas. Todo ello a la luz de la jurisprudencia del TJUE.

Palabras clave: Derecho a la no autoincriminación, Procedimiento administrativo sancionador, Unión Europea, personas jurídicas.

Abstract: The right not to incriminate oneself is configured as a fundamental right integrated in the broadest right of defense and it is recognized in the most important international treaties of our legal environment. Its operability in the framework of criminal proceedings is not in doubt, nor is its transfer to the scope of the administrative sanctioning procedure. However, the purpose of this paper will be to analyze the scope of the right to remain silent and not to confess guilt in administrative proceedings, not only in the administrative santioning proceedings, but also in inspection proceedings, as well as its operability in relation to legal entities. All this in the light of the jurisprudence of the CJEU.

Keywords: The right not to incriminate oneself, Administrative Sanctions Procedure, European Union, legal entities. 


\section{INTRODUCCIÓN}

Tal y como indica el Diccionario Jurídico de la RAE el derecho a no autoincriminarse es el derecho fundamental del acusado -en el procedimiento penal o administrativo sancionador- a no declarar contra sí mismo y a no confesarse culpable. Igualmente comprende el derecho a guardar silencio. En definitiva, tal y como lo determinó el Tribunal Constitucional español se trata de una garantía fundamental cuyo "contenido esencial se identifica como un derecho a no ser condenado o sancionado con fundamento en la información autoincriminatoria aportada bajo coacción" ${ }^{\text {. }}$

En principio, parece que el citado derecho fundamental podría aplicarse sin matices en el proceso penal, sin embargo, plantea más interrogantes su adaptación al procedimiento administrativo sancionador. Consideramos interesante abordar este análisis puesto que en el ámbito administrativo ha de conjugarse el derecho a la no autoincriminación con los deberes legales que tiene el administrado de colaborar con la Administración, en ocasiones, con amenaza de sanción.

Con objeto de la celebración del III Congreso Internacional de Jóvenes investigadores sobre la Unión Europea que tendrá lugar el 7 y 8 de octubre en Valladolid centraremos nuestro análisis de la cuestión en el ámbito del derecho comunitario donde cada vez son más los procesos judiciales donde se invoca este derecho, sobretodo en el ámbito tributario o del derecho de la competencia.

La primera vez que el Tribunal de Justicia de las Comunidades Europeas -hoy TJUE- aludía al derecho a la no autoincriminación en el ámbito administrativo sancionador -aunque no de forma explícita- fue en la STJCE de 21 de septiembre de 1989, (Caso Hoechst A. G. contra Comisión de las Comunidades Europeas), cuyo parágrafo 15 disponía "que el derecho de defensa debe ser respetado en los procedimientos administrativos que pueden dar lugar a una sanción, ha de evitarse, al mismo tiempo, que el mencionado derecho quede irremediablemente dañado en los procedimientos de investigación previa, especialmente en las verificaciones, que pueden tener un carácter determinante para la constitución de pruebas del carácter ilegal de conductas de las empresas susceptibles de generar la responsabilidad de éstas”.

${ }^{1}$ STC 18/2005, de 1 de febrero, AH 3. 
A partir de ahí, y apoyándose continuamente en la doctrina del Tribunal Europeo de Derechos Humanos (en adelante, TEDH), han sido múltiples los pronunciamientos del TJUE sobre el derecho a guardar silencio y a no confesarse culpable. El objeto de este trabajo es precisamente, mediante el análisis de esta jurisprudencia, tratar delimitar el contenido o alcance de este derecho en el procedimiento administrativo sancionador en el ámbito comunitario.

\section{EL DERECHO FUNDAMENTAL A LA NO AUTOINCRIMINACIÓN COMO MANIFESTACIÓN DEL DERECHO DE DEFENSA}

\section{1. Regulación}

La práctica totalidad de los ordenamientos de los Estados Miembros de la Unión reconocen en sus Constituciones el derecho a no declarar contra uno mismo y a no confesarse culpable con rango de derechos fundamentales integrados en un genérico derecho de defensa o entre las garantías de un proceso justo y equitativo ${ }^{2}$. Concretamente, en el caso español, el artículo 24.2 de la Constitución, sitúa entre las garantías fundamentales de la tutela judicial efectiva y del debido proceso el derecho "a no declarar contra sí mismo[s], a no confesarse culpable[s] y a la presunción de inocencia".

En el ámbito internacional, el artículo 14.3.g) del Pacto Internacional de Derechos Civiles y Políticos consagra como garantías mínimas del proceso, de forma expresa, los derechos de toda persona "a no ser obligada a declarar contra sí misma ni a confesarse culpable”.

Por su parte, en el ámbito europeo y comunitario, llama la atención que ni el Convenio Europeo de Derechos Humanos (en adelante, CEDH) ni la Carta de los Derechos Fundamentales de la Unión Europea hagan alusión expresa al derecho a la no autoincriminación. Sin embargo, de la

2 El Tribunal Constitucional español así lo ha reiterado en diversas ocasiones considerando que "los derechos a no declarar contra sí mismo y a no confesarse culpable... son garantías o derechos instrumentales del genérico derecho de defensa, al que prestan cobertura en su manifestación pasiva, esto es, la que se ejerce precisamente con la inactividad del sujeto sobre el que recae o puede recaer una imputación, quien, en consecuencia, puede optar por defenderse en el proceso en la forma que estime más conveniente para sus intereses, sin que en ningún caso pueda ser forzado o inducido, bajo constricción o compulsión alguna, a declarar contra sí mismo o a confesarse culpable”. Vid., entre otras, STC 23/2014, de 13 de febrero, FJ 4, o STC 181/2020, de 14 de diciembre, FJ 2. 
doctrina del TEDH se desprende, inequívocamente, "que el derecho a guardar silencio y el derecho a no confesarse culpable, aunque no expresamente mencionados en el artículo 6 del Convenio ${ }^{3}$, son normas reconocidas internacionalmente, que residen en el corazón mismo del

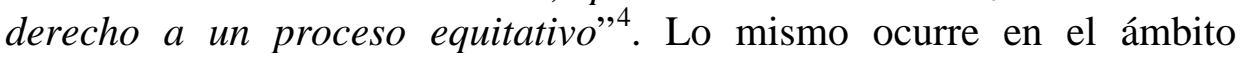
comunitario que, sin estar previstas expresamente estas garantías en los artículos 47 y 48 de la Carta $^{5}$ relativos al derecho a la tutela judicial

${ }^{3} \mathrm{El}$ artículo $6 \mathrm{CEDH}$ que consagra las garantías fundamentales del debido proceso determina: “1. Toda persona tiene derecho a que su causa sea oída equitativa, públicamente y dentro de un plazo razonable, por un Tribunal independiente e imparcial, establecido por la Ley, que decidirá los litigios sobre sus derechos y obligaciones de carácter civil o sobre el fundamento de cualquier acusación en materia penal dirigida contra ella. La sentencia debe ser pronunciada públicamente, pero el acceso a la Sala de Audiencia puede ser prohibido a la prensa y al público durante la totalidad o parte del proceso en interés de la moralidad, del orden público o de la seguridad nacional en una sociedad democrática, cuando los intereses de los menores o la protección de la vida privada de las partes en el proceso así lo exijan o en la medida considerada necesaria por el Tribunal, cuando en circunstancias especiales la publicidad pudiera ser perjudicial para los intereses de la justicia. 2. Toda persona acusada de una infracción se presume inocente hasta que su culpabilidad haya sido legalmente declarada. 3. Todo acusado tiene, como mínimo, los siguientes derechos: a) a ser informado, en el más breve plazo, en una lengua que comprenda y detalladamente, de la naturaleza y de la causa de la acusación formulada contra él; b) a disponer del tiempo y de las facilidades necesarias para la preparación de su defensa; c) a defenderse por sí mismo o a ser asistido por un defensor de su elección y, si no tiene medios para pagarlo, poder ser asistido gratuitamente por un Abogado de oficio, cuando los intereses de la justicia lo exijan; d) a interrogar o hacer interrogar a los testigos que declaren contra él y a obtener la citación y el interrogatorio de los testigos que declaren en su favor en las mismas condiciones que los testigos que lo hagan en su contra; e) a ser asistido gratuitamente de un intérprete, si no comprende o no habla la lengua empleada en la Audiencia.

${ }^{4}$ STEDH de 21 de diciembre de 2000, $n^{\circ}$ 40, (caso Quinn contra Irlanda). En el mismo sentido, vid. STEDH de 24 d octubre de 2013, $\mathrm{n}^{\circ}$ 71, (caso Navone y otros contra Mónaco).

${ }^{5}$ El artículo 47 (derecho a la tutela judicial efectiva y a un juez imparcial) dispone que "toda persona cuyos derechos y libertades garantizados por el Derecho de la Unión hayan sido violados tiene derecho a la tutela judicial efectiva respetando las condiciones establecidas en el presente artículo. Toda persona tiene derecho a que su causa sea oída equitativa y públicamente y dentro de un plazo razonable por un juez independiente e imparcial, establecido previamente por la ley. Toda persona podrá hacerse aconsejar, defender y representar. Se prestará asistencia jurídica gratuita a quienes no dispongan de recursos suficientes siempre y cuando dicha asistencia sea necesaria para garantizar la efectividad del acceso a la justicia”. Por su parte, el artículo 48 (presunción de inocencia y derechos de la defensa) considera que “1. Todo acusado se presume inocente mientras 
efectiva, al juez imparcial, a la presunción de inocencia y al derecho de defensa, se consideran implícitamente incluidos en ellos y nadie duda de su plena aplicación en el ámbito de la Unión.

El mismo Tratado de la Unión Europea, en su artículo 6.3 reconoce que "los derechos fundamentales que garantiza el Convenio Europeo para la Protección de los Derechos Humanos y de las Libertades Fundamentales y los que son fruto de las tradiciones constitucionales comunes a los Estados miembros formarán parte del Derecho de la Unión como principios generales”. A mayor abundamiento, en el derecho derivado sí se reconoce de forma expresa el derecho a guardar silencio y el derecho a no declarar contra sí mismo. Concretamente, con carácter general para el ámbito penal, el considerando número 27 de la Directiva 2016/343, de 9 de marzo, por la que se refuerzan en el proceso penal determinados aspectos de la presunción de la inocencia y el derecho a estar presente en el juicio, considera que a fin de determinar si se han vulnerado los derechos anteriormente "debe tenerse en cuenta la interpretación por el Tribunal Europeo de Derechos Humanos del derecho a un juicio justo en virtud del CEDH" ${ }^{\circ}$.

\subsection{Contenido}

A partir del principio latino nemo tenetur se ispsum acussare surgen el derecho a guardar silencio, el derecho a no confesarse culpable o el derecho a no declarar contra uno mismo, todos muy relacionados entre sí y todos también íntimamente ligados al principio de presunción de inocencia ${ }^{7}$. Una vez aclarado el rango de garantía fundamental del

su culpabilidad no haya sido declarada legalmente. 2. Se garantiza a todo acusado el respeto de los derechos de la defensa”.

6 También se hace referencia al derecho a no declarar contra sí mismo y a guardar silencio de forma explícita en la Directiva 2016/800, de 11 de mayo, relativa a las garantías procesales de los menores sospechosos o acusados en los procesos penales, en los considerandos 29 y 31. Y no solo en el ámbito penal, sino también el artículo 9.2 del Reglamento 883/2013, de 11 de septiembre, relativo a las investigaciones efectuadas por la Oficina Europea de Lucha contra el Fraude (OLAF) reconoce que "la Oficina (Europea de Lucha contra el fraude) podrá oír a la persona de que se trate o a un testigo en todo momento durante la investigación. A las personas oídas les asiste el derecho a no autoinculparse”.

${ }^{7}$ Así se desprende de la jurisprudencia del TEDH. Vid., STEDH de 25 de febrero de 1993, (Caso Funke contra Francia), STEDH de 8 de febrero de 1996, (Caso John 
derecho a la no autoincriminación en cualquiera de sus formulaciones dentro del más amplio derecho de defensa-, así como su vigencia y aplicación en el ámbito del Derecho de la Unión Europea, nos disponemos a continuación a tratar de delimitar su alcance o contenido dentro del debido proceso.

\subsubsection{El derecho a permanecer en silencio}

Primeramente, y antes de entrar en el contenido del derecho a guardar silencio propiamente dicho, tanto un sector doctrinal como la jurisprudencia del TEDH coinciden en que el derecho a la no autoincriminación comienza con el deber que recae sobre las autoridades -tanto en el ámbito penal ${ }^{8}$ como en el administrativo- de informar al acusado de su derecho a guardar silencio y no declarar contra sí mismo al inicio del procedimiento ${ }^{9}$. Por tanto, la ausencia de la puesta en conocimiento del acusado de la posibilidad de ejercer su derecho a no autoincriminarse durante el procedimiento sancionador ya supone una vulneración del mismo ${ }^{10}$.

Dicho lo cual, el derecho a guardar silencio implica, al menos dos facultades:

- La primera de ellas es la de permanecer callado respetando la voluntad del acusado de no contestar a las preguntas que se le

Murray contra Reino Unido) o STEDH de 17 de diciembre de 1996, (Caso Saunders contra Reino Unido).

${ }^{8}$ En el ámbito penal lo reconoce expresamente el artículo 3 de la Directiva 2012/13/UE de 22 de mayo relativa al derecho a la información en los procesos penales que establece que "los Estados miembros garantizarán que las personas sospechosas o acusadas reciban con prontitud información acerca, como mínimo de los siguientes derechos procesales” entre los que destaca en la letra e) el derecho a permanecer en silencio.

${ }^{9}$ Cfr. Alarcón Sotomayor, Lucía, (2007), "El procedimiento administrativo sancionador y los derechos fundamentales”, Civitas, Cizur Menor, p. 197, quien cita también la STC 197/2005, de 21 de diciembre donde se consagra que las autoridades "deben ilustrar desde el primer acto procesal en el que pueda dirigirse contra una determinada persona el procedimiento, (el derecho) de no prestar declaración en contra de sí mismo y de no confesar la culpabilidad”.

${ }^{10}$ Vid. STEDH de 24 d octubre de 2013, (caso Navone y otros contra Mónaco), donde se considera vulnerado el artículo $6 \mathrm{CEDH}$-concretamente el derecho a la no autoincriminación- por la "ausencia de notificación a los señores Navone y Lafleur de su derecho a permanecer en silencio durante su detención preventiva”. 
formulen. En otras palabras, no es admisible ningún tipo de presión o práctica coercitiva por parte de la autoridad que pueda desembocar en una declaración autoinculpatoria ${ }^{11}$.

- La segunda facultad que comprende el derecho a guardar silencio del imputado es la de decidir prestar declaración o realizar alegaciones, así como contestar total o parcialmente a las preguntas que le sean formuladas. Es decir, el derecho a permanecer callado otorga al acusado la facultad de decidir libremente sobre si quiere o no quiere realizar alegaciones y sobre su contenido ${ }^{12}$. En caso afirmativo, toda declaración del imputado sólo se podrá obtener válidamente cuando éste decida prestarla libremente.

Por último debemos abordar, aunque sea someramente, la problemática de si el derecho a guardar silencio -o a prestar declaraciónincluye el derecho a mentir o a no decir la verdad. Parece que el Tribunal Constitucional español no presenta dudas al respecto entendiendo que dentro del más amplio derecho de defensa del acusado está el de "callar total o parcialmente o incluso mentir" 13 pues "a diferencia del testigo, no sólo no tiene obligación de decir la verdad sino que puede (...) mentir, en virtud de los derechos a no declarar contra sí mismo y a no confesarse culpable" ${ }^{14}$.

La realidad es que no existe ninguna norma nacional o internacional que se pronuncie al respecto $\mathrm{y}$, hasta lo que hemos podido averiguar, tampoco el TEDH ni el TJUE tienen pronunciamientos tan explícitos como los citados del TC español. Sin embargo, de la interpretación del derecho a no confesarse culpable, de plena aplicación en la Unión Europea como principio general como ya se señaló supra, podemos deducir que se desprende un derecho, al menos, a no decir la verdad. De no admitirse esto, todo acusado -culpable- que no optase por ejercer su

\footnotetext{
${ }^{11}$ Vid. STEDH de 21 de diciembre de 2000, no 40, (Caso Heaney y McGuinness contra Irlanda): "The right not to incriminate oneself is primarily concerned, however, with respecting the will of an accused person to remain silent” o, en el mismo sentido, STEDH de 4 de octubre de 2005, n 40, (Caso Shannon contra Reino Unido).

12 Cfr. Alarcón Sotomayor, Lucía, (2007), “El procedimiento administrativo sancionador...” op. cit. p. 193.

${ }^{13}$ Vid., STC 170/2006, de 5 de junio, FJ 4 o STC 142/2009, de 15 de junio, FJ 6.

${ }^{14}$ Vid., STC 68/2001, de 17 de marzo, FJ 5 o STC 17/2004, de 23 de febrero, FJ 3.
} 
legítimo derecho a guardar silencio debería confesarse culpable y si, por el contrario, ejercitase su derecho a permanecer callado equivaldría a una confesión implícita de culpabilidad ${ }^{15}$.

Incluso en un procedimiento de inspección -no punitivo- donde se exija un deber de cooperación con la autoridad bajo amenaza de sanción cuyo cumplimiento equivaldría claramente a la autoinculpación, la entrega de documentación falsa -sin perjuicio de que pueda constituir un delito de falsedad documental- o las declaraciones inexactas podrían no sancionarse si en el procedimiento punitivo posterior se acreditase que esta conducta fue debida al ejercicio del derecho a no autoincriminarse ${ }^{16}$.

\subsubsection{El derecho a no confesarse culpable}

Una segunda facultad del derecho a la no autoincriminación la conforma el derecho a no confesarse culpable, cuyo alcance, además del puramente literal que permite al imputado no confesarse culpable o, $a$ contrario sensu, declararse inocente, implica además el derecho a no colaborar contra uno mismo durante la vigencia del procedimiento sancionador, penal o administrativo.

Por lo tanto, supone una vulneración del derecho a la no autoincriminación el hecho de obligar a responder al acusado determinadas preguntas capciosas cuya respuesta implique admitir la existencia de una infracción. Y lo mismo cabe concluir de la aportación de documentos bajo coerción, cuando su aportación tenga inequívocamente carácter autoincriminatorio ${ }^{17}$. En definitiva, conculcará el derecho a no confesarse culpable cualquier actuación exigida

${ }^{15}$ En este sentido, cfr. Rebollo Puig, Manuel, Izquierdo Carrasco, Manuel, Alarcón Sotomayor, Lucía y Bueno Armijo, Antonio María, (2010), “Derecho Administrativo Sancionador", Lex Nova, Valladolid, p. 602.

${ }^{16}$ Cfr. Gómez Tomillo, Manuel, (2019), “Instrumentos jurídicos de tutela y ejecución de las potestades de inspección y supervisión administrativa de sociedades que operan en los mercados. Artículo 294 CP. Entrada y registro domiciliario con ocasión de investigación de infracciones administrativas”, Thomson Reuters Aranzadi, Cizur Menor, p. 114.

${ }^{17}$ Cfr. Palao Taboada, Carlos, (2008), El derecho a no autoinculparse en el ámbito tributario, Thomson Civitas, Cizur Menor, p. 25, para quien, si se obtuvieran coactivamente del imputado declaraciones o documentos autoincriminatorios, éstos nunca podrán servir de base para la condena o sanción. 
coactivamente por la autoridad al acusado que convierta a éste en una fuente de prueba autoinculpatoria ${ }^{18}$.

Baste decir por el momento que las situaciones descritas hasta ahora son producidas en el marco de un procedimiento sancionador. La cuestión adquiere muchos más matices, como veremos a continuación, cuando se trate de procedimientos de inspección o comprobación previos - $\mathrm{o}$ no- a un procedimiento sancionador.

\subsubsection{La prohibición de valorar el ejercicio del derecho a la no autoincriminación contra el imputado}

Por último, en este breve recorrido sobre el alcance del derecho a la no autoincriminación queremos concluir advirtiendo que el ejercicio legítimo de un derecho -en este caso el de guardar silencio o no confesarse culpable- no podrá, en ningún caso, determinar consecuencias desfavorables o sancionadoras para quien lo ejerce ${ }^{19}$.

Ahora bien, tampoco se trata de un derecho absoluto $\mathrm{y}$, las autoridades penales o administrativas podrán valorar o tener en cuenta, junto con el resto de pruebas practicadas en el procedimiento, el silencio o la pasividad del acusado.

En este sentido es clarificadora la STEDH de 8 de febrero de 1996 (Caso Murray contra Reino Unido) cuyo parágrafo 47 determina que "es manifiestamente incompatible con las prohibiciones de las que se trata basar una condena exclusiva o esencialmente en el silencio del acusado o sobre su negativa a responder a las cuestiones o a declarar. Por otro, es también evidente para el Tribunal que esas prohibiciones no pueden y no deberían impedir tener en cuenta el silencio del interesado, en situaciones que requieren seguramente una explicación por su parte, para apreciar la fuerza de persuasión de los elementos de cargo. Se sitúe donde se sitúe la línea de demarcación entre estos dos extremos, se deriva de esta interpretación del «derecho a guardar silencio» que hay que responder negativamente a la pregunta de si este derecho es absoluto".

\footnotetext{
${ }^{18}$ Cfr. Banacloche Palao, Julio, (2000), "El derecho a ser informado de la acusación, a no declarar contra uno mismo y a no confesarse culpable", Cuadernos de Derecho Público, nº 10, p. 196.

${ }^{19}$ Cfr. Gómez Tomillo, Manuel, (2019), “Instrumentos jurídicos de tutela y ejecución de las potestades de inspección... op. cit. p. 95.
} 
En consecuencia, no será posible basar una resolución sancionadora en el único argumento del ejercicio legítimo de un derecho del acusado, pero sí podrá formar parte de la valoración global de todo el material probatorio, especialmente en aquellos asuntos en que fuese especialmente determinantes las explicaciones del acusado.

\section{EL TRASLAdO DEL DERECHO A LA NO AUTOINCRIMINACIÓN DEL ÁMBITO PENAL AL ÁMBITO ADMINISTRATIVO SANCIONADOR}

Es ya clásica la idea de que "los principios inspiradores del orden penal son de aplicación, con ciertos matices, al derecho administrativo sancionador, dado que ambos son manifestaciones del ordenamiento punitivo del Estado" ${ }^{20}$. En efecto, el derecho a la no autoincriminación no es una excepción; nace como garantía fundamental en el orden penal y debe aplicarse, mutatis mutandi, al derecho administrativo sancionador ${ }^{21}$.

No sólo en el ámbito nacional rige esta máxima. De hecho, el TEDH ha repetido en numerosos pronunciamientos que "las exigencias generales de justicia contenidas en el artículo 6.1 CEDH, incluido el derecho a no autoinculparse, se aplican en todos los procedimientos punitivos concernientes a todos los tipos de ilícitos criminales sin distinción: desde el delito más complejo hasta la infracción más simple"22. En este mismo sentido, y nutriéndose de la doctrina elaborada por el TEDH, también el TJUE ha puesto de manifiesto la operatividad del derecho a la no autoincriminación en el ámbito administrativo sancionador $^{23}$.

${ }^{20}$ STC 18/1981, de 8 de junio, FJ 2.

${ }^{21}$ En relación con el traslado de los principios inspiradores del orden penal al ámbito administrativo sancionador, cfr. Gómez Tomillo, Manuel y Sanz Rubiales, Iñigo, (2017), Derecho administrativo sancionador. Parte General, $4^{\mathrm{a}}$ Ed., Thomson Reuters Aranzadi, Cizur Menor, pp. 115 y ss.

22 STEDH de 17 de diciembre de 1996, n 74, (Caso Saunders contra Reino Unido). En el mismo sentido, vid. STEDH de 21 de diciembre de 2000, n 58, (Caso Quinn contra Irlanda).

${ }^{23}$ La primera vez que el TJUE -entonces TJCE- admitió de forma explícita a escala europea algunos de los efectos inherentes a las garantías contra la autoincriminación en el ámbito del procedimiento administrativo sancionador fue en la STJCE de 18 de octubre de 1989, (Caso Orkem contra Comisión). Entre los pronunciamientos más recientes, destacamos la STJUE de 2 de febrero de 2021, n ${ }^{\circ}$ 42, (Asunto C-481/19), que establece que el derecho a la no autoincriminación "debe aplicarse en el contexto de procedimientos que pueden dar lugar a la imposición de sanciones administrativas”. 
En definitiva, una vez comprobado que el derecho a la no autoincriminación es aplicable a cualquier tipo de procedimiento sancionador, abordaremos a continuación la cuestión de las posibles modulaciones o matices que éste puede tener en el ámbito administrativo.

Parece complicado, en principio, modular el derecho a guardar silencio y a no declarar contra sí mismo dentro del ámbito de un procedimiento punitivo pues de la propia naturaleza del mismo se desprende su carácter absoluto. En otras palabras, resulta difícil matizar o graduar tanto el derecho a guardar silencio -o se guarda silencio o nocomo el derecho a no confesarse culpable $-\mathrm{o}$ se aporta información autoincriminatoria o no- ${ }^{24}$.

Sin embargo, podría contemplarse la posibilidad de modular el derecho a no autoincriminarse de los administrados en relación con el cumplimiento de deberes legales de colaboración con la Administración bajo amenaza de sanción que pueden surgir en el marco de procedimientos inspectores o de comprobación. Puede ocurrir -los procedimientos de comprobación tributarios o los de defensa de la competencia son claros ejemplos- que surja, a priori, una contradicción entre el deber legal de colaboración con la Administración que obliga al administrado a entregar ciertos documentos bajo amenaza de sanción si, posteriormente, la información contenida en esos documentos resulta autoincriminatoria para un procedimiento sancionador posterior.

Baste decir por el momento, antes de analizar el concreto alcance del derecho que analizamos en el marco de procedimientos no sancionadores -inspección o comprobación- que tampoco en estos supuestos nos parece justificable relajar o matizar la garantía de la no autoincriminación en el ámbito administrativo en relación con el ámbito penal. Es decir, el hecho de encontrarnos ante un procedimiento administrativo no sancionador no equivale automáticamente a renunciar a la garantía de no autoincriminación pues se desconocen las consecuencias del cumplimiento del deber de colaboración del administrado. Es posible que

\footnotetext{
${ }^{24}$ Incidiendo en la idea de que no caben matices ni modulaciones en el procedimiento administrativo sancionador sobre el derecho a la no autoincriminación, García de Enterría, Eduardo y Fernández, Tomás Ramón, (2020), Curso de Derecho Administrativo II, 16 ad., Thomson Reuters Civitas, Cizur Menor, p. 218, consideran que "la carga de la prueba es entera de la Administración, que concentra las funciones de acusador y decisor, y el procedimiento es enteramente contradictorio, con la plenitud de los derechos constitucionales de defensa (entre ellos el derecho a la no autoincriminación)”.
} 
el cumplimiento del deber de colaboración no tenga consecuencias sancionadoras pero, también es posible que implique la apertura de un procedimiento administrativo sancionador 0 , incluso, de un proceso penal $^{25}$. Por lo tanto, el hecho de desconocer las posibles consecuencias sancionadoras del cumplimiento del deber de colaboración administrativas o penales- impide modular el derecho a la no autoincriminación que deberá operar siempre con la misma intensidad.

En conclusión, el derecho a permanecer en silencio y a no declarar contra uno mismo no puede presentar un contenido o intensidad diferentes en el ámbito penal o en el ámbito administrativo sancionador. Ahora bien, no está reñida esta afirmación con reconocer que la garantía de la no autoincriminación desplegará su eficacia plena en los procedimientos punitivos ${ }^{26}$-penales o administrativos- y podrá verse matizada en los procedimientos inspectores o de comprobación puesto que debe conjugarse con los deberes legales de colaboración con la Administración bajo amenaza de sanción.

\section{EL ALCANCE DE LA GARANTÍA DE NO AUTOINCRIMINACIÓN EN EL MARCO DEL PROCEDIMIENTOS ADMINISTRATIVOS DE INSPECCIÓN O COMPROBACIÓN}

Como hemos adelantado en el epígrafe anterior, se trata de conjugar el derecho fundamental a la no autoincriminación con los deberes legales de colaboración con la Administración, teniendo en cuenta que no nos encontramos en el marco de procedimientos sancionadores pero que, es posible, que del material aportado bajo amenaza de sanción en el procedimiento de inspección puede surgir un procedimiento punitivo, penal o administrativo.

\subsection{La operatividad del derecho a la no autoincriminación en los procedimientos administrativos no punitivos}

Por una parte, hemos de partir de la premisa de que no cabe alegar el ejercicio legítimo del derecho fundamental a no declarar contra uno mismo cuando, en el seno de un procedimiento no sancionatorio, se exige

\footnotetext{
25 Cfr. Alarcón Sotomayor, Lucía, (2007), “El procedimiento administrativo sancionador...” op. cit. p. 186.

${ }^{26}$ Íbidem. p. 188.
} 
por la Administración al administrado el cumplimiento del deber legal de aportar cierta documentación bajo amenaza de sanción. Y no puede ser de otro modo, puesto que de lo contrario estaríamos desarmando a la Administración que, simple y llanamente, no podría ejercitar su potestad inspectora en ningún caso ${ }^{27}$.

El propio TJUE ha reconocido que "el derecho a guardar silencio no puede justificar cualquier falta de cooperación con las autoridades competentes" $^{28}$. Por lo tanto, en el seno de procedimientos administrativos no sancionadores no podrá, por regla general, invocarse válidamente el derecho fundamental a la no autoincriminación pues primaría el deber de colaboración con la Administración frente al derecho a no declarar contra sí mismo. Ahora bien, esta regla general merece, al menos, un matiz ya que el deber de colaboración tampoco tiene, ni puede tener, un carácter absoluto.

Ciertamente, puede ser plenamente invocable el derecho a no declarar contra uno mismo cuando, pese a no estar formalmente incurso en un procedimiento de naturaleza sancionadora, la Administración requiere una documentación a un sujeto con un fin exclusivamente incriminatorio $^{29}$. Esto es, prevalece el derecho a la no autoincriminación frente al deber de colaboración con la Administración cuando ésta requiere documentación en un procedimiento no punitivo con indudable intención de abrir inmediatamente después un procedimiento sancionador basado en el material obtenido bajo amenaza de sanción ${ }^{30}$.

La jurisprudencia del TEDH viene a subrayar este matiz pues considera que, al margen de un procedimiento punitivo, no existe vulneración del derecho a no declarar contra uno mismo cuando se requiere coactivamente -por ejemplo, con la imposición de multas- a un

${ }^{27}$ Cfr. Gómez Tomillo, Manuel, (2019), “Instrumentos jurídicos de tutela y ejecución de las potestades de inspección... op. cit. p. 101.

${ }^{28}$ STJUE de 2 de febrero de 2021, no 41, (Asunto C-481/19), concretamente especifica como conductas incompatibles con el derecho a no autoincriminarse la negativa a presentarse a una audiencia o la utilización de maniobras dilatorias para aplazarla.

${ }^{29}$ Cfr. Aguallo Avilés, Ángel y Bueno Gallardo, Esther, (2008), "El contenido del derecho a no autoincriminarse: en especial, divergencias entre la Jurisprudencia del Tribunal Constitucional Español y la del Tribunal Europeo de Derechos Humanos”, Estudios jurídicos en memoria de don César Albiñana García-Quintana, Vol II, Instituto de Estudios Fiscales, Madrid, pp.1378 y 1379.

${ }^{30}$ Cfr. Gómez Tomillo, Manuel, (2019), “Instrumentos jurídicos de tutela y ejecución de las potestades de inspección... op. cit. p. 106 y Alarcón Sotomayor, Lucía, (2007), “El procedimiento administrativo sancionador...” op. cit. p. 227. 
administrado a facilitar una información si no existe un vínculo concreto entre la información facilitada y el procedimiento sancionador inmediatamente posterior. Es decir, si la conexión entre el deber de colaborar y el procedimiento sancionador es remota e hipotética no habrá vulneración del derecho de defensa ${ }^{31}$.+

También en esta línea se encuentra el TJUE, considerando que el derecho a la no autoincriminación puede verse vulnerado en un procedimiento administrativo de inspección si la información obtenida está relacionada directamente con la confesión de una infracción y la apertura inmediata del procedimiento sancionador. Concretamente, la STJCE de 18 de octubre de 1989, (Caso Orkem contra Comisión), en su parágrafo 33, en un asunto de defensa de la competencia considera que ha de evitarse que el derecho a la no autoincriminación "quede irremediablemente dañado en los procedimientos de investigación previa, que puedan tener un carácter determinante para la constitución de pruebas del carácter ilegal de conductas de las empresas susceptibles de generar la responsabilidad de éstas. Por consiguiente, si bien algunas manifestaciones del derecho de defensa afectan únicamente a los procedimientos contradictorios que siguen a una comunicación de los cargos imputados, otras deben ser respetadas ya en la fase de investigación previa". Y, en consecuencia, declara vulnerado el derecho de defensa cuando las respuestas a las preguntas que realizó la Comisión a una empresa en el seno de un procedimiento de investigación iban encaminadas, pura y llanamente, a confesar una infracción.

\subsection{La utilización del material obtenido mediante la inspección administrativa como prueba en un procedimiento sancionador posterior: los límites derivados del derecho a no declarar contra uno mismo}

Ya hemos podido observar cómo tanto la jurisprudencia del TEDH como del TJUE admiten, aunque excepcionalmente, la vulneración del derecho a guardar silencio y no confesarse culpable en el marco de un procedimiento de inspección siempre que haya una conexión estrecha o inmediata entre el material obtenido en el procedimiento de inspección o comprobación y el sancionador posterior.

${ }^{31}$ STEDH de 8 de abril de 2004, no 56, (Caso Weh contra Austria) y STEDH de 24 de marzo de 2005, $n^{\circ}$ 31, (Caso Rieg contra Austria). 
Al margen de estas situaciones, lo que trataremos de analizar a continuación es el papel que puede desempeñar el material obtenido en un procedimiento de inspección en un procedimiento sancionador posterior $^{32}$. O, dicho de otro modo, trataremos de responder a la pregunta de si puede utilizarse en contra del acusado en un procedimiento punitivo la información facilitada por él mismo bajo amenaza de sanción en un procedimiento de inspección anterior y hasta qué punto es compatible esa práctica con el derecho a la no autoincriminación.

Partiremos de la base de que, en principio, la información testimonios o documentos-obtenida en un procedimiento de inspección sí podría ser utilizada como material probatorio en contra de quien la aportó en un procedimiento sancionador ulterior ${ }^{33}$. Nadie puede ignorar que una de las principales funciones de la potestad inspectora de la Administración es la detección de infracciones y que la citada potestad está sometida también al principio de legalidad. En consecuencia, no existe un fundamento sólido que impida utilizar como prueba el material obtenido conforme a Derecho en un procedimiento inspector ${ }^{34}$. Ahora bien, la obtención de ese material durante la inspección no puede deberse a fines exclusivamente incriminatorios por parte de la Administración, pues ello vulneraría el derecho de defensa del acusado. Para despejar dudas acerca de esta posibilidad se deberán tener en cuenta dos extremos:

32 El ámbito tributario presenta la posibilidad de tramitación simultánea de un procedimiento de liquidación y el sancionador en los supuestos de renuncia a la tramitación separada del procedimiento. En estos casos, cfr. Palao Taboada, Carlos, (2008), El derecho a no autoinculparse... op. cit. pp. 205 y 206, entiende que “el contribuyente tiene derecho a saber en cuál de los dos procedimientos se enmarcan las actuaciones” en aplicación del principio -de tradición jurídica alemana- de claridad procedimental. En virtud del citado principio el órgano administrativo debe informar al administrado de la posibilidad de que una información requerida puede ser autoincriminatoria y, en consecuencia, del derecho a guardar silencio y a no declarar contra sí mismo.

${ }^{33}$ En esta línea se ha pronunciado también el Auto del TJUE de 24 de septiembre de 2019, $n^{\circ} 34$, (Caso QR contra varios), donde se considera que se reconoce a los Estados Miembros, "en el contexto del derecho a guardar silencio y del derecho a no declarar contra sí mismo, la facultad de permitir a sus autoridades judiciales que, al dictar una sentencia que imponga una sanción, tomen en consideración el comportamiento cooperador de sus acusados”.

34 Cfr. Alarcón Sotomayor, Lucía, (2007), "El procedimiento administrativo sancionador...” op. cit. p. 232. 
- Por un lado, el derecho a la no autoincriminación no otorga cobertura cuando lo obtenido es información heteroincriminatoria, y no autoincriminatoria ${ }^{35}$. El derecho a no declarar contra uno mismo desplegará su eficacia cuando se trate de declaraciones de voluntad estrictamente autoinculpatorias, es decir, cuando contengan una declaración de culpabilidad de su autor contra sí mismo. Por ello, cuando se trate de información inculpatoria obtenida coactivamente de terceros no existirá obstáculo legal alguno para utilizarla como material probatorio en un procedimiento punitivo.

Por ello, es preferible, especialmente en el ámbito tributario, que la Administración practique actividades inspectoras sin requerimientos coactivos, pues el derecho a la no autoincriminación no puede invocarse frente al deber de soportar una actividad comprobadora como podría ser la ejecución de una entrada y registro en el domicilio de una persona física o jurídica con las preceptivas autorizaciones ${ }^{36}$.

- Por otro lado, el material obtenido en el procedimiento de inspección debe tener una existencia independiente a la voluntad de quien resulta posteriormente acusado ${ }^{37}$. En esta idea ha incidido el TEDH considerando que no habrá vulneración del derecho de defensa si el contenido del material obtenido en un procedimiento de inspección, aun de forma coactiva, es objetivo,

${ }^{35}$ En el ámbito del derecho a la no autoincriminación de las personas jurídicas, cfr. Gómez Tomillo, Manuel, (2019), “Instrumentos jurídicos de tutela y ejecución de las potestades de inspección... op. cit. p. 102.

${ }^{36}$ En relación con los procedimientos de comprobación y sancionadores tributarios, cfr. Aníbarro Pérez, Susana y Sesma Sánchez, Begoña, (2005), Infracciones y sanciones tributarias, Lex Nova, Valladolid, p. 236.

${ }^{37}$ En esta línea, en el ámbito penal, la Directiva 2016/343, de 9 de marzo, por la que se refuerzan en el proceso penal determinados aspectos de la presunción de inocencia y el derecho a estar presente en el juicio, anteriormente citada, en el considerando 29 establece que "El ejercicio del derecho a no declarar contra sí mismo no debe impedir a las autoridades competentes recabar las pruebas que puedan obtenerse legalmente del sospechoso o acusado mediante el ejercicio legítimo de poderes coercitivos, y que tengan una existencia independiente de la voluntad del sospechoso o acusado, como por ejemplo el material obtenido con arreglo a una orden judicial, el material respecto del que exista una obligación legal de retención o entrega a petición de la autoridad, como las muestras de aliento, sangre, orina y tejidos corporales para el análisis del ADN”. 
es decir, independiente de la voluntad de la persona a quien pueda perjudicar. Por ejemplo, una prueba de alcoholemia o una muestra de ADN nunca podrán constituir una declaración contra uno mismo pues se trata de datos independientes a la voluntad del investigado y posteriormente acusado ${ }^{38}$.

En definitiva, la razón de ser de la potestad inspectora de la Administración Pública permite que el material obtenido pueda tener validez probatoria, como regla general, en un procedimiento sancionador. Sin embargo, la garantía de la no autoinculpación puede verse afectada cuando el propósito o finalidad de la inspección sea la apertura inmediata de un procedimiento sancionador basado precisamente en el material obtenido que la Administración desconocía y no tenía otra posibilidad de averiguar sino obteniéndolo coactivamente del propio administrado en un procedimiento inspector $^{39}$.

\section{EL DERECHO A LA NO AUTOINCRIMINACIÓN DE LAS PERSONAS JURÍDICAS}

Por último, haremos referencia al derecho a la no autoincriminación en relación con las personas jurídicas. No nos detendremos, por no ser objeto del presente trabajo, en el debate sobre la titularidad de los derechos fundamentales de las personas jurídicas, cuestión que damos por sentada en relación con el derecho a guardar silencio y no declarar contra sí mismo ${ }^{40}$. En efecto, toda vez que las personas jurídicas pueden

\footnotetext{
${ }^{38}$ La famosa STEDH de 17 de diciembre de 1996, $\mathrm{n}^{\circ}$ 69, (Caso Saunders contra Reino Unido) consideró que el derecho a declarar contra sí mismo no entra en juego cuando lo obtenido mediante poderes coactivos tiene una existencia independiente de la voluntad del acusado, y cita como ejemplos, las muestras de aliento, sangre, orina o de ADN. En el mismo sentido, STEDH de 3 de mayo de 2001, $n^{\circ}$ 68, (Caso J. B. contra Suiza).

${ }^{39}$ Cfr. Palao Taboada, Carlos, (2008, El derecho a no autoinculparse... op. cit. p. 207.

${ }^{40}$ En el caso español, el artículo 786 bis LECrim establece que "cuando el acusado sea una persona jurídica, ésta podrá estar representada para un mejor ejercicio del derecho de defensa por una persona que especialmente designe, debiendo ocupar en la Sala el lugar reservado a los acusados. Dicha persona podrá declarar en nombre de la persona jurídica si se hubiera propuesto y admitido esa prueba, sin perjuicio del derecho a guardar silencio, a no declarar contra sí mismo y a no confesarse culpable, así como ejercer el derecho a la última palabra al finalizar el acto del juicio”. Así también lo reconoce ampliamente por toda la doctrina, cfr., entre otros, González López, Juan José, (2016), “Imputación de personas jurídicas y derecho a la no colaboración activa”,
} 
resultar imputadas o acusadas en un procedimiento sancionador -penal ${ }^{41}$ o administrativo-, parece que también tendrán derecho a ejercitar el derecho de defensa en sus múltiples vertientes dentro de dicho procedimiento.

Por ello, en este momento simplemente trataremos de averiguar el alcance o las particularidades que el derecho a la no autoincriminación puede presentar en el ámbito del procedimiento administrativo sancionador de las personas jurídicas. Precisamente el parágrafo 48 de la reciente STJUE de 2 de febrero de 2021, (Asunto C-481/19), pone de manifiesto que los razonamientos aportados por este mismo tribunal en "procedimientos que pueden dar lugar a la imposición de sanciones a empresas y asociaciones de empresas no puede aplicarse por analogía cuando se trata de determinar el alcance del derecho a guardar silencio de personas físicas".

En relación al alcance de la garantía de no autoincriminación, y volviendo sobre el carácter absoluto de ésta, pocas matizaciones caben, a nuestro juicio, entre el derecho a la no autoincriminación de las personas físicas y de las personas jurídicas. En definitiva, el contenido de este derecho es idéntico independientemente de quien sea su titular y coincide con el ya analizado más arriba, a saber; el derecho a permanecer en silencio, a no aportar información autoinculpatoria bajo coacción y a no verse perjudicado por el ejercicio legítimo de las dos vertientes anteriores del derecho a la no autoincriminación en el seno de un procedimiento sancionador. Y, excepcionalmente, también en el seno de un procedimiento no punitivo -de comprobación o inspección- si de la información solicitada bajo amenaza de sanción se desprendiera

Revista Jurídica de Castilla y León, $\mathrm{n}^{\circ}$ 40, pp. 60 y ss, y también en el ámbito del procedimiento administrativo sancionador, cfr. Rebollo Puig, Manuel, Izquierdo Carrasco, Manuel, Alarcón Sotomayor, Lucía y Bueno Armijo, Antonio María, (2010), "Derecho... op.cit. p. 557.

Del mismo modo, en el ámbito comunitario se ha reconocido desde el principio el comentado derecho, así lo atestigua, entre otras, la anteriormente citada STJCE de 18 de octubre de 1989, (Caso Orkem contra Comisión) que reconoce a favor de una empresa su derecho a no autoinculparse.

${ }^{41}$ Dentro del ámbito de la Unión Europea una gran mayoría de los países contemplan la responsabilidad penal de las personas jurídicas en sus respectivas normas penales salvo Alemania que, tratándose de una excepción no menor, sin embargo está tramitando en la actualidad un proyecto de ley que contempla esta posibilidad (Entwurf eines Gesetzes zur Bekämpfung der Unternehmenskriminalität). 
inequívocamente responsabilidad y se conectase inmediatamente con un procedimiento sancionador.

Ahora bien, los matices surgen a partir de la evidencia de que una persona jurídica no puede actuar por sí misma y necesita de personas físicas que lo hagan por ella. Es decir, quién puede ejercer válidamente el derecho a la no autoincriminación de una sociedad.

No plantea dudas, en principio, el hecho de que los sujetos formalmente autorizados para actuar por cuenta de la sociedad representantes legales y/o administradores con poderes para actuar en nombre de la sociedad- son el alter ego de la misma y, en consecuencia, podrán ejercitar sus derechos sin que pueda cuestionarse su ejercicio en representación de la persona jurídica ${ }^{42}$.

La cuestión no ofrece la misma claridad, sin embargo, si quien se niega a declarar o a entregar cierta documentación requerida es un directivo, mando intermedio o subordinado de la persona jurídica. Siguiendo en este punto a GÓMEZ TOMILLO consideramos que también estos cargos podrán ejercitar el derecho a la no autoincriminación de la sociedad por varias razones; en primer lugar, porque en la actualidad existen estructuras societarias de tal complejidad organizativa y volumen de personal que resulta ilusorio pensar que la decisión del ejercicio del derecho que analizamos deba, en todo caso, ejercitarse únicamente por sus representantes legales. Y, en segundo lugar, porque los sistemas penales que reconocen responsabilidad penal y, con más razón, administrativa- a las personas jurídicas también otorgan, normalmente, capacidad para cometer infracciones a los mandos intermedios $\mathrm{y}$, en consecuencia, si pueden cometer infracciones en nombre de la sociedad, también deberían poder ejercer sus derechos ${ }^{43}$.

Para concluir, aludiremos brevemente a la problemática de cuándo podrán los representantes legales y demás personas físicas autorizadas ejercer el derecho a la no autoincriminación de las personas jurídicas de las que forman parte. La solución no difiere de la que podría darse para

${ }^{42}$ Cfr. Gómez Tomillo, Manuel, (2019), “Instrumentos jurídicos de tutela y ejecución de las potestades de inspección... op. cit. p. 117, quien además, acertadamente a nuestro juicio, pone de manifiesto que la situación de quién puede ejercer el derecho a la no autoincriminación de la persona jurídica no plantea problemas cuando “el sujeto interrogado pueda ser personalmente responsable penal o administrativo porque en esta situación la negativa a declarar está inequívocamente cubierta por el derecho a no autoincriminarse".

43 Íbidem. pp. 103 y 104. 
las personas físicas. Es evidente, pues estamos ante el ejercicio de un derecho de defensa, que podrá invocarse siempre en el marco de un procedimiento de carácter sancionador, ya sea penal o administrativo sancionador. Es decir, las autoridades no podrán solicitar bajo amenaza de sanción -o podrá hacerse caso omiso a esa solicitud- durante un procedimiento punitivo ningún tipo de información de la persona jurídica a sus representantes legales, administradores o directivos.

Ahora bien, al margen de los procedimientos sancionadores, los representantes legales de las personas jurídicas sí tienen el deber de cooperar con los requerimientos de las autoridades -pudiendo ser sancionados si no lo hacen- con la única salvedad de que de la contestación a las preguntas o aporte de documentación se desprendiera inequívocamente responsabilidad punitiva de la persona jurídica. En estos casos, el derecho a la no autoincriminación anticiparía su operatividad ante la inminente apertura de un procedimiento sancionador con el único fundamento de la información aportada por el representante legal de la sociedad.

No mantiene una postura tan garantista el TJUE que, sorprendentemente a nuestro juicio, ha manifestado recientemente que incluso "en el marco de un procedimiento sancionador (...) se puede obligar a la empresa implicada a que facilite toda la información necesaria relacionada con hechos de los que pueda tener conocimiento y a que presente, si fuere preciso, los documentos correspondientes que obren en su poder, incluso si estos pueden servir para probar, en particular respecto de la propia empresa, la existencia de una conducta contraria a la competencia" ${ }^{44}$.

Por todo lo expuesto hasta ahora, no podemos compartir la posición del Tribunal de Luxemburgo que sí parece disminuir en gran medida casi eliminar- el contenido de la garantía de no autoincriminación de las personas jurídicas, toda vez que permite obligar en un procedimiento sancionador a una empresa a facilitar información aunque pueda evidenciar una infracción. Consideramos que todos los matices que merece este derecho en relación con las personas jurídicas van orientados a quién puede o no ejercerlo en su nombre, pero no al contenido, que no debería ponerse en duda. Si se admite que las personas jurídicas tienen capacidad legalmente reconocida de cometer infracciones administrativas -y penales en casi la totalidad de países de nuestro entorno-, parece

${ }^{44}$ STJUE de 2 de febrero de 2021, nº 46, (Asunto C-481/19). 
lógico que no puede dudarse de que también deben gozar de la plenitud de garantías que el derecho de defensa -reconocido en toda su amplitud en el ámbito comunitario como hemos visto al comienzo del presente trabajo- otorga a quien se enfrenta a un procedimiento sancionador, ya sea una persona física o jurídica.

\section{BIBLIOGRAFÍA}

Aguallo Avilés, Ángel y Bueno Gallardo, Esther, (2008), “El contenido del derecho a no autoincriminarse: en especial, divergencias entre la Jurisprudencia del Tribunal Constitucional Español y la del Tribunal Europeo de Derechos Humanos”, Estudios jurídicos en memoria de don César Albiñana García-Quintana., Vol II, Instituto de Estudios Fiscales, Madrid.

Alarcón Sotomayor, Lucía, (2007), "El procedimiento administrativo sancionador y los derechos fundamentales”, Civitas, Cizur Menor.

Aníbarro Pérez, Susana y Sesma Sánchez, Begoña, (2005), Infracciones y sanciones tributarias, Lex Nova, Valladolid.

Banacloche Palao, Julio, (2000), "El derecho a ser informado de la acusación, a no declarar contra uno mismo y a no confesarse culpable”, Cuadernos de Derecho Público, nº 10.

García de Enterría, Eduardo y Fernández, Tomás Ramón, (2020), Curso de Derecho Administrativo II, 16 ${ }^{\mathrm{a}}$ Ed., Thomson Reuters Civitas, Cizur Menor.

Gómez Tomillo, Manuel y Sanz Rubiales, Iñigo, (2017), Derecho administrativo sancionador. Parte General, $4^{\mathrm{a}}$ Ed., Thomson Reuters Aranzadi, Cizur Menor.

Gómez Tomillo, Manuel, (2019), "Instrumentos jurídicos de tutela y ejecución de las potestades de inspección y supervisión administrativa de sociedades que operan en los mercados. Artículo 294 CP. Entrada y 
registro domiciliario con ocasión de investigación de infracciones administrativas”, Thomson Reuters Aranzadi, Cizur Menor.

González López, Juan José, (2016), “Imputación de personas jurídicas y derecho a la no colaboración activa”, Revista Jurídica de Castilla y León, $\mathrm{n}^{0} 40$.

Palao Taboada, Carlos, (2008), El derecho a no autoinculparse en el ámbito tributario, Thomson Civitas, Cizur Menor.

Rebollo Puig, Manuel, Izquierdo Carrasco, Manuel, Alarcón Sotomayor, Lucía y Bueno Armijo, Antonio María, (2010), "Derecho Administrativo Sancionador”, Lex Nova, Valladolid. 